\title{
Design criteria for outdoor air intakes and exhaust air outlets located on an external wall
}

\author{
Ülar Palmiste ${ }^{1, *}$, Jarek Kurnitski ${ }^{1,2}$, and Hendrik Voll ${ }^{1}$ \\ ${ }^{1}$ Tallinn University of Technology, Department of Civil Engineering and Architecture Ehitajate tee 5, 19086 Tallinn, Estonia \\ ${ }^{2}$ Aalto University, School of Engineering, Rakentajanaukio 4 A, FI-02150, Espoo, Finland
}

\begin{abstract}
Optimal placement of outdoor air intakes and exhaust outlets is a source control measure to avoid the degradation of air quality at the air intakes. Re-entrainment is an occasional air pollution instance that happens if pollutants in the exhaust air stream, after being discharged to outdoors, are transferred back to outdoor air intake location due to unfavorable meteorological conditions and inadequate positioning of the air intakes and exhaust outlets. In engineering practice, it is impractical to always conduct detailed dispersion modeling due to the complexity of airflow phenomena in the urban environments, and therefore, engineers rely on prescriptive design guidelines or simplified empirical models published in technical literature and regulation documents. Commonly, the design guidelines to avoid the re-entrainment phenomenon are for buildings with rooftop exhaust stacks, but the exhaust outlets might also be situated on the building façade. The objective of this paper is to overview the existing design guidelines for the placement of horizontal air intakes and exhaust outlets. Technical engineering literature, including international standards, codes, and guidebooks is reviewed to extract both qualitative and quantitative design guidelines relevant to the placement of air intakes and exhausts on an external wall.
\end{abstract}

\section{Introduction}

In developed countries, the inhalation of indoor air contaminants by the building occupants constitutes a significant fraction of the total personal exposure to environmental pollution during a person's lifetime [1]. Mechanical ventilation is an engineered exposure control strategy that uses the introduction of outdoor air and a simultaneous displacement of pollutants through the extraction of stale air from the space to the outdoor environment to maintain concentrations below levels that does not negatively affect the perceived air quality, productivity, and health of the building occupants.

In ventilation design, a basic premise is that the outdoor air is 'clean', but in urban environments, the quality of outdoor air varies in spatial and temporal distribution around the building because of the proximity to traffic, vicinity of local pollution sources, and pollution from neighboring buildings or the building itself [2]. Ventilation exhaust air re-entrainment is an episodic air pollution event which occurs when the discharged exhaust air is transported back into the building through ventilation air intakes or other openings in the building enclosure [3] and it can potentially induce indoor air quality problems from comfort issues like nuisance due to odors to re-entry of pollutants that are harmful to health [4]. The issue of contaminant transfer from an exhaust outlet to the outdoor air intake in different building types with mechanical ventilation has been reported in several studies, including single-family and multifamily residential buildings [5-12] and nonresidential buildings [13-16]. In addition, re-entrainment has been extensively studied in buildings with singlesided natural ventilation where airborne transmission of infectious biological aerosols [17,18], particulate matter [19] and gaseous contaminants [20,21] route has been shown from one dwelling unit to another through open windows via outdoor air along the external wall due to the effect of wind and buoyancy. Therefore, proper consideration should be given to the correct specification of designated outdoor air intakes and exhaust outlets to minimize the risk of indoor air pollution caused by the re-entry of contaminants previously discharged from the ventilation exhaust outlet to the outdoor environment.

In ventilation design practice, it is often impractical to conduct time-intensive exhaust air dispersion simulations due to the complexity of airflow phenomena around buildings in urban environments. Engineers rely on various technical guidelines, building codes, and standards that have been established to provide a reference in the ventilation design process to mitigate the risk of outdoor pollutant entry, including re-entrainment. The conventional design recommendation in regards to locating the ventilation exhaust outlets is to use a rooftop stack with enough height to discharge the exhaust airstream upwards so that it penetrates the rooftop recirculation region. However, the economical disadvantage of this design is that the exhaust ducts must run through a building to the roof which increases the ventilation systems capital cost, operating cost because

* Corresponding author: ular.palmiste@ taltech.ee 
of energy use due to increased pressure drop in the ducting, and alternative cost for dedicating space and floor area for duct runs instead of other building space usages. Therefore, the industry is interested in a reevaluation of current requirements that focus on rooftop exhausts to assess the viability of alternative design solutions for locating exhaust outlets, such as discharging exhaust horizontally through the external wall [22]. Recent research efforts to improve the exhaust design process to mitigate the re-entrainment risk have mainly focused on rooftop stack exhausts [16,23-26], but different ventilation exhaust configurations have remained nearly unstudied in the scientific literature [4,27].

The objective of the paper is to present an overview of existing guidelines that could be implemented for the placement of air intakes and exhaust outlets on building façade with a particular focus on mechanical ventilation system design. The survey is limited to technical guidance from major international standards, codes, and guidebooks. The work presented here is a part of a wider research project on near-field pollutant dispersion from exhaust air terminals located on vertical surfaces of a building.

\section{Contaminant transfer from horizontal exhausts}

Ventilation exhaust air stream that is discharged in a horizontal plane from the exhaust outlet forms a turbulent air jet that initially moves away from the wall surface because of its momentum but then is gradually slowed down by contact with the surrounding outdoor air which is introduced into the primary jet airstream as secondary air. The interaction of wind and building creates complex airflow patterns around the building, as illustrated in simplified form in Fig. 1. In addition to wind-induced flow, during the sunny days, the solar radiation can heat the building façade and elevated surface temperatures cause convective flow along the façade upwards. These turbulent airflows vastly influence the near-field dispersion of pollutants in the exhaust air jet as they can be transferred by advection and diluted by turbulent diffusion.

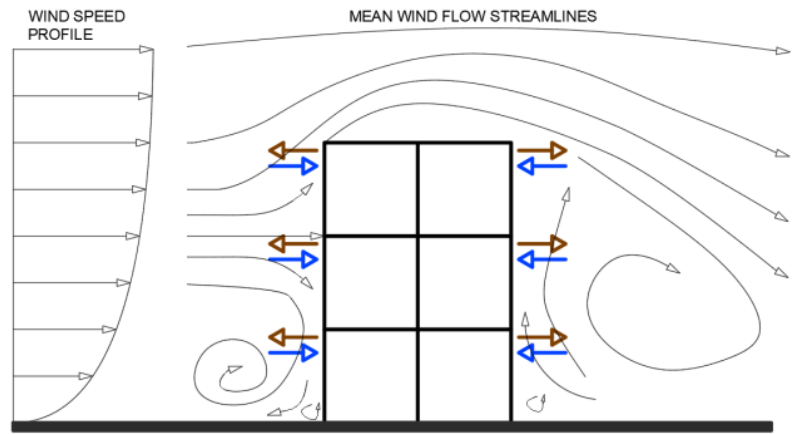

Fig. 1. Mean airflow pattern around a building

In comparison to rooftop stacks, the exhaust outlets on a façade have zero or minimal height because they are flush with the facade for aesthetic considerations. Also, they are often covered with protective shields for precipitation. For these reasons, the exhaust jet might lack the momentum to travel a safe distance from the building surface and the pollutants could get trapped in recirculation zones, either on the windward or leeward side of the building, or transmitted to outdoor air intakes with downwash, upwash or convective flows. The principle of re-entrainment is schematically described in Fig. 2.

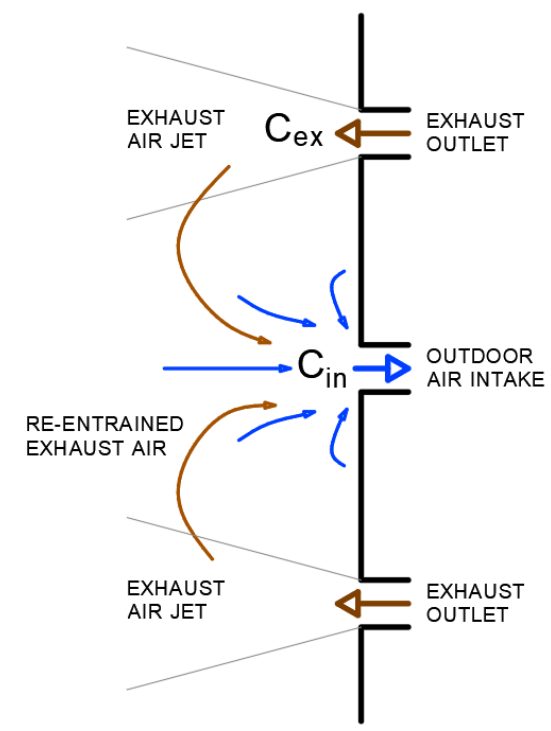

Fig. 2. Schematic representation of re-entrainment

Re-entrainment ratio $\mathrm{R}$ can be used to quantify the fraction of pollutants from the source (exhaust airstream) that transfer to the receptor (outdoor air intake) location and re-enter the building. $\mathrm{R}$ can be calculated as a concentration ratio as follows:

$$
\mathrm{R}=\mathrm{C}_{\mathrm{in}} / \mathrm{C}_{\mathrm{ex}}
$$

where

$C_{\text {in }}$ pollutant concentration at the air intake, $\mu \mathrm{g} / \mathrm{m}^{3}$ $C_{e x}$ pollutant concentration at the air exhaust, $\mu \mathrm{g} / \mathrm{m}^{3}$.

The exhaust dilution factor is the inverse of the reentrainment ratio and is defined as the ratio of exhaust concentration to the concentration at in air intake:

$$
\mathrm{D}=1 / \mathrm{R}=\mathrm{C}_{\mathrm{ex}} / \mathrm{C}_{\mathrm{in}}
$$

If there is a background concentration of a contaminant in the outdoor air, it can be substituted from the pollutant concentration at the intake location to account only for exhaust re-entrainment.

The design of a ventilation exhaust outlet that discharges horizontally and is placed on the same wall with the air intake involves specifying the outdoor terminal device locations, separation distance and exhaust flow parameters to minimize the re-entrainment ratio while also taking into account the constraints of local meteorological conditions, building geometry, surrounding urban environment and aesthetic considerations. 


\section{Results}

The purpose of ventilation standards and codes is to establish a common basis for decision-making in the ventilation design process by typically setting minimum quality criteria to provide acceptable indoor air quality. The following sections overview the relevant technical information for specifying ventilation exhaust air opening and outdoor air intakes on a façade.

\subsection{Qualitative guidelines}

\subsubsection{General recommendations}

Outdoor air quality might not be uniform around the building and thus, intakes should be situated in the least polluted location considering the existing and planned pollution sources, to minimize the risk of outdoor pollutants entering the ventilation system [28-31]. In urban landscapes, finding a suitable location for the air intake can be challenging because of traffic pollution in the street canyons, and in case of such busy streets, the air intake should be located as high as possible or on the facades away from the street [29,31]. Ventilation terminals on the external wall should not be located near edges of walls or roofs due to pressure fluctuations [30].

Re-entrainment into the same or adjacent building should be refrained from by careful design of terminals or by adequate spatial separation distance [28,29,32]. The required minimum separation distance depends on the characterization of pollutants in the exhaust air stream and the exhaust flow rate [29], but the more distant the intake is from the exhaust discharge point, the smaller is the risk of re-entrainment [30]. Locating exhaust air terminals within architectural screens must be avoided as it may cause higher pollutant concentration levels in the recirculation region that could form within the enclosure [30]. As a rule, intakes should not be located in the same architectural screen enclosure as exhaust outlets [31].

Ventilation exhaust air should be discharged from such location that it will not cause a public nuisance close to the building on walkways, terraces, etc. $[28,32,33]$.

\subsubsection{Air intakes and exhaust outlets on a facade}

If outdoor air quality is uniform on both sides of the building, the intake should be located on the windward side [29], but on the other hand, locating the air intakes high and away from the predominant wind direction extends the filter life [30]. The air inlets and exhaust outlets should be located so that the impact of wind and buoyancy are minimized [29,31]. Considering the effects of normal wind separation and resulting upward and downward flows along the facade, the intakes should be positioned on the lower third and exhausts on the upper third of the building, but possible recirculation region on the lower third on the leeward side should be taken into account [30,34]. Through-the-wall exhaust outlets are permitted if the smoke, grease, gases, vapors, and odors in the discharge from such terminations do not create a public nuisance or a fire hazard [32]. The exhaust air stream from commercial kitchen hood should be directed perpendicularly outward from the wall face or upward [33]. Rooftop exhaust stack should be used for category EHA 4 air which is harmful to health [28].

The air intake should be below the exhaust outlet if they are located on the same façade to avoid reentrainment [29]. The risk of pollutants re-entry can also be reduced by locating the terminals on different facades, but varying wind forces on terminal openings may negatively affect fan performance [30].

\subsection{Quantitative guidelines}

Prescriptive design guidelines from international standards, codes, and guidebooks are systematized and presented in Table 1. Mostly, the design requirements are established as minimum separation distances between pollution sources (s) and receptors (r). Specifying separation distances is an indirect approach for maintaining the pollutant concentrations below safe levels at the air intake because the prescriptive separation distances are general for a wide range of situations and not determined for specific design scenarios.

In Table 1, the outdoor air intake is a pollutant receptor classification that includes both the dedicated air intakes and exhausts of a mechanical ventilation system and also the openings that are part of a natural ventilation system. Operable openings are receptors that account for windows and doors. Besides receptors that are located on the same building surface as pollution sources, the receptors could also be on the adjacent surfaces or neighboring buildings. For that reason, the required separation distances from contaminant sources to adjacent walls, opposite walls of neighboring buildings, and distance to property lot lines are frequently specified.

Exhaust outlets can be categorized by the exhaust air characteristics. ASHRAE divides extracted indoor air into four classes that describe the level of air contamination within the space. Class 2 air is moderately contaminated or odorous and is restricted in its recirculation. Class 3 air is significantly polluted including unpleasant odors, and potentially dangerous contaminants, such as extract air from residential kitchen hoods. Class 4 contains highly objectionable fumes, potentially dangerous particles, bioaerosols, or gases at concentrations high enough to be considered harmful to health, such as laboratory hoods and commercial grease hoods. European ventilation standard EN 16798-3 uses EHA classification for describing exhaust air types that are analogous to ASHRAE four air classes.

There are only a few guidelines that specify parameter values for exhaust airflow rate or speed. Performance targets in the form of minimum dilution factors and maximum re-entrainment ratios are also scarce. 


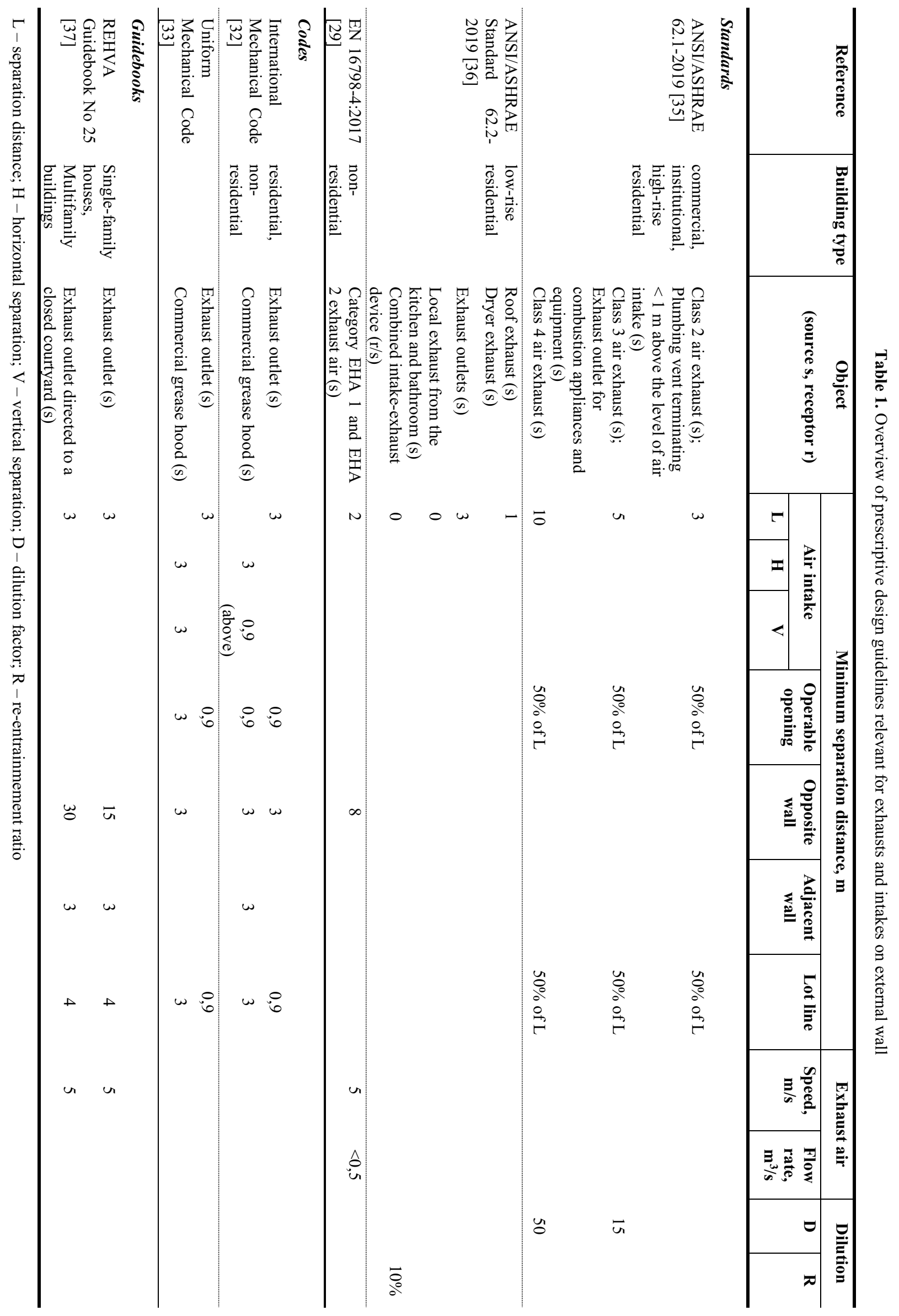




\subsection{Calculation methods}

This section provides an overview of different calculation methods for specifying exhaust outlets and outdoor air intakes.

\subsubsection{ASHRAE standard 62.1}

ASHRAE standard 62.1 describes two alternative approaches for specifying outdoor air intakes and exhaust outlets in addition to prescriptive separation distances. First, the velocity method determines the required separation distance $\mathrm{L}$ as follows:

$$
L=0,04 \cdot \sqrt{Q} \cdot\left(\sqrt{D F}-\frac{U}{2}\right)
$$

where

$Q \quad$ exhaust air volumetric flow rate, $1 / \mathrm{s}$

$D F$ dilution factor using volume fraction concentration $U$ exhaust air velocity, $\mathrm{m} / \mathrm{s}$

Exhaust air velocity $U$, depending on the exhaust airstream direction in relation to the air intake, can be either positive, negative, or zero. The $\mathrm{U}$ value is positive for horizontal exhaust through a wall.

Dilution factor DF is is the volume fraction of outdoor air to entrained exhaust air in the outdoor air intake as described by equation 2 :

$$
\mathrm{DF}=\mathrm{Q}_{\text {out }} / \mathrm{Q}
$$

where

$Q_{\text {out }}$ volumetric fraction of outdoor air in the intake, $1 / \mathrm{s}$.

Minimum dilution factor values for different exhaust air classes are presented in Table 1.

If the exhaust air contains several classes of air, the dilution factor is calculated by averaging the DF-s by the volume fraction of each air class as follows :

$$
\mathrm{DF}=\sum\left(\mathrm{DF}_{\mathrm{i}} \cdot \mathrm{Q}_{\mathrm{i}}\right) / \sum \mathrm{Q}_{\mathrm{i}}
$$

where

$D F_{i}$ dilution factor for class i air

$Q_{i} \quad$ volumetric flow rate of class i air in the exhaust air.

The second analytical method, concentration method, is a health-based approach that first defines acceptable concentrations for pollutant emissions that do not induce odor complaints or risks to health. Exhaust outlets and air intakes are designed so that the maximum exhaust concentrations do not exceed the acceptable concentrations for odors and health.

$$
\begin{aligned}
& \mathrm{C}_{\max }<\mathrm{C}_{\text {health }} \\
& \mathrm{C}_{\max }<\mathrm{C}_{\text {odor }}
\end{aligned}
$$

where

$C_{\max }$ maximum concentration at the air intake, $\mu \mathrm{g} / \mathrm{m}^{3}$ $C_{\text {health }}$ acceptable concentration for health, $\mu \mathrm{g} / \mathrm{m}^{3}$ $C_{o d o r}$ acceptable concentration for odor, $\mu \mathrm{g} / \mathrm{m}^{3}$

According to the standard, the modeling for the maximum concentration must include wind speed and direction, exhaust air velocity and momentum, building geometry including neighboring structures and architectural screens.

\subsubsection{EN 16798-4}

According to the method provided in the reference, the minimum separation distances between intake and exhaust openings can be derived from the dilution factor $f$ that is defined as:

$$
f=\frac{\sqrt{q_{v} \text { or } B}}{C_{1} \cdot l+C_{2} \cdot \Delta h}
$$

where

$f \quad$ dilution factor

$q_{v} \quad$ exhaust air flow rate, $1 / \mathrm{s}$

$B$ capacity of a chimney/outlet of a heating system in $\mathrm{kW}$

$l$ distance between air intake and exhaust outlet

$\Delta h$ difference in height between the air intake and exhaust outlet

$C_{1}, C_{2}$ dilution coefficients (situation dependent)

For non-residential applications with the exhaust and intake through the wall, separation distance can be found by the graphical tool below.

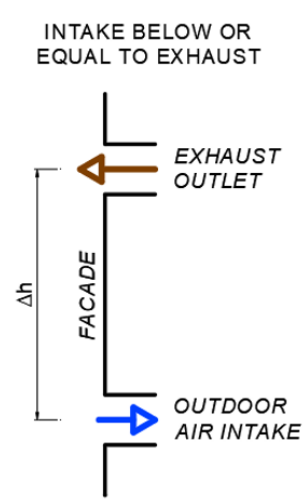

EHA 1-2: $2 l+\Delta h>0,308 \cdot \sqrt{ } q_{v}$ EHA 3: I $>0,2 \cdot \sqrt{ } q_{v}$

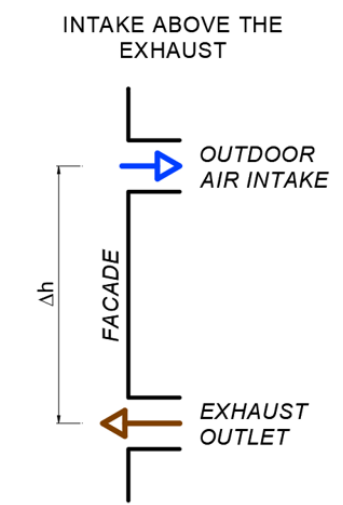

EHA 1-2: $3,07 I-\Delta h>0,613 \cdot \sqrt{ } q$ EHA 3: $1,54 l-\Delta h>0,308 \cdot \sqrt{ } q_{v}$
Fig. 3. Minimum separation between exhaust outlet and air intake on an external wall for exhaust airflow rates $<0,5 \mathrm{~m}^{3} / \mathrm{s}$ [29]

EN 16798-4:2017 presents another graphical method (Fig. 4) for determining the minimum recommended distance between the exhaust outlet and outdoor air intake for exhaust airflow rate larger than $0,5 \mathrm{~m}^{3} / \mathrm{s}$.

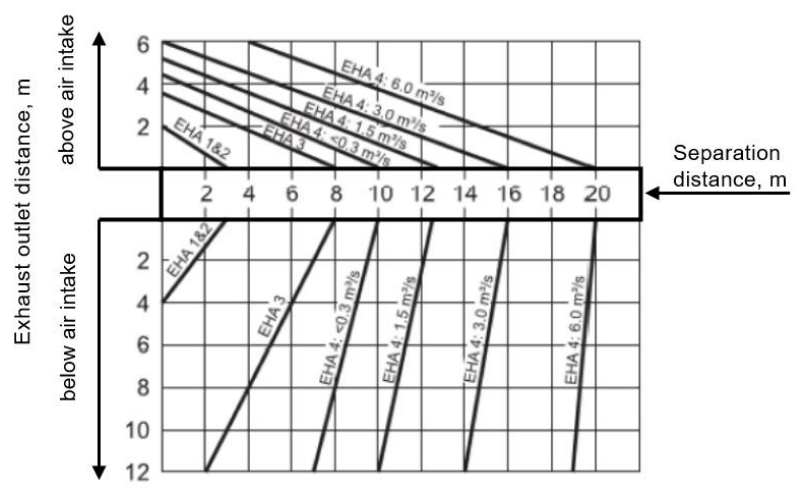

Fig. 4. Minimum separation between exhaust outlet and outdoor air intake for exhaust airflow rates $>0,5 \mathrm{~m}^{3} / \mathrm{s}$ [29] 


\subsubsection{ASHRAE Handbook}

The chapter "Building air intake and exhaust design" in ASHRAE Handbook describe a method for calculating dilution from a flush exhaust outlet which in turn could be converted to pollutant concentration and thus, compared to relevant limit values [31].

$$
D=\frac{4 U_{H} \sigma_{y} \sigma_{z}}{V_{e} d_{e}^{2}}
$$

where

$D$ dilution at a wall intake from a flush exhaust outlet $U_{H}$ mean wind speed at height $\mathrm{H}$ of an upwind wall, $\mathrm{m} / \mathrm{s}$

$\sigma_{y} \quad$ standard deviation of cross-wind plume spread, $\mathrm{m}$

$\sigma_{z} \quad$ standard deviation of vertical plume spread, $\mathrm{m}$

$V_{e} \quad$ air velocity at exhaust outlet, $\mathrm{m} / \mathrm{s}$

$d_{e}^{2} \quad$ effective exhaust outlet diameter, $\mathrm{m}$

Lateral and vertical plume spread is found by:

$$
\begin{gathered}
\sigma_{y}=\sqrt{\left(i_{y}^{2} x^{2}+\sigma_{0}^{2}\right)} \\
\sigma_{z}=\sqrt{\left(i_{z}^{2} x^{2}+\sigma_{0}^{2}\right)}
\end{gathered}
$$

where

$i_{y} \quad$ lateral turbulence intensity

$i_{z} \quad$ vertical turbulence intensity

$x$ downwind horizontal distance from the center of outlet to the receptor location, $\mathrm{m}$

$\sigma_{0}$ standard deviation of initial plume spread at the exhaust used to account for initial dilution, $\mathrm{m}$.

Initial source size $\sigma_{0}$ is normally set as:

$$
\sigma_{0}=0,35 \cdot d_{e}
$$

Turbulence intensities are calculated as follows:

$$
\begin{gathered}
i_{y}=0,75 \cdot i_{x} \\
i_{z}=0,5 \cdot i_{x}
\end{gathered}
$$

where

$$
i_{x}=\frac{n \ln \left(\frac{30}{z_{0}}\right)}{\ln \left(\frac{Z}{z_{0}}\right)}
$$

where

$z \quad$ vertical distance, $\mathrm{m}$

$z_{0} \quad$ roughness length, $\mathrm{m}$

$n$ coefficient

Roughness length $z_{0}$ is selected based on the terrain characteristics. Coefficint $\mathrm{n}$ is calculated as below:

$$
n=0,24+0,096 \cdot \log _{10}\left(z_{0}\right)+0,016 \cdot\left(\log _{10}\left(z_{0}\right)\right)^{2}
$$

\subsection{Comparison between methods}

Different prescriptive and analytical methods were compared by applying them in a test case to specify the separation distance between air intake and exhaust outlet. Methods for both residential and non-residential applications are applied although, in practice, an appropriate method depending on the building function should be used.
Table 2. Test case description

\begin{tabular}{ll}
\hline Parameter & Value \\
\hline System & Decentralized ventilation unit \\
characterization & with integrated cooker hood \\
Pollutant & Class EHA 3 air (16798-3); \\
& Class 3 air (ASHRAE 62.1) \\
Exhaust outlet location & Same external wall \\
Exhaust duct diameter & $160 \mathrm{~mm}$ \\
Exhaust flow rate & $80 \mathrm{l} / \mathrm{s}$ \\
Exhaust flow speed & $4,0 \mathrm{~m} / \mathrm{s}$ \\
& \\
\hline
\end{tabular}

The prescriptive and analytically calculated separation distances are depicted in Fig. 4. Some analytical methods require a dilution target as an input assumption and in these cases, the separation distances for different dilution factors were calculated. Also, the ASHRAE dilution model included the characterization of the urban terrain type.

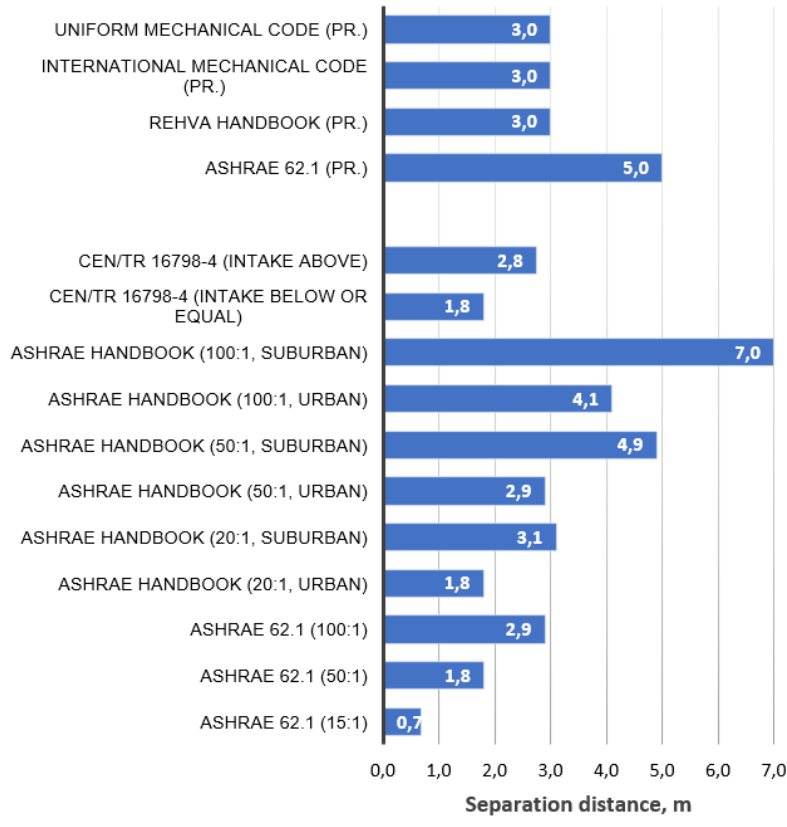

Fig. 5. Comparison of separation distances specified by different methods for air intake and exhaust outlet located on the same external wall (pr. - prescriptive guidelines; above/below/equal - relative location of intake in regards to exhaust outlet; urban/suburban - terrain category; 100:1/50:1/20:1/15:1 - dilution factor)

For the given situation, prescriptive separation distances were in the range of $3-5 \mathrm{~m}$, but with the analytical tools, the largest separation was 10 times greater than the smallest specified separation length.

\section{Discussion}

Qualitative recommendations can be considered as a rule-of-thumb approach for determining intake and outlet locations in the early design phase, but if they are not accompanied by quantitative engineering guidance or dispersion modeling tools then qualitative guidelines alone might remain inconclusive to assess if the 
proposed design meets the set objectives and quality criteria.

The background of individual quantitative requirements in technical guidance literature often remains uncertain because the guidelines lack references and therefore it is difficult to evaluate the underlying basis and limitations for specific requirements that vary depending on the literature source. Thus, it is unclear how sensitive the prescriptive minimum recommended separation distance and analytical calculation methods are to influencing factors such as meteorological conditions and surrounding urban environment, the relative position of exhausts and intakes on an external wall, and architectural features of the façade. The variation

Some wind tunnel and computational fluid dynamics (CFD) studies have been conducted to evaluate and propose improvements to certain design guidelines for rooftop stack emissions, but evidence-based research is lacking for near-field pollutant dispersion and reentrainment from an exhaust outlet located on an external wall. Evaluation studies are required to assess the strictness or mildness of existing design guidelines and calculation methods for various practical intake and exhaust configurations. Also, current recommendations are not comprehensive because the information for some design configurations, such as combined exhaust-intake devices, is unavailable.

\section{Conclusion}

The paper presented an overview of qualitative and quantitative technical guidelines, and analytical calculation methods applicable to specifying outdoor air intakes and exhaust outlets that are located on a facade. The guidelines were compared by implementing them in a test case to determine the required separation distance to avoid exhaust re-entrainment.

The variation among the guidelines that lead to different minimum separation distance requirements illustrates the uncertainties associated with utilizing the prescriptive guidelines and analytical calculation methods. Consequently, there is a knowledge gap for testing and evaluating the validity of current design methods for ventilation system intake and exhaust terminals that are located on an external wall. Researchbased recommendations are needed to support the improvement of the future revisions of different ventilation standards and building regulations for greater uniformity.

This research was supported by the Estonian Research Council, with Personal research funding grant PUT -652 and by the Estonian Centre of Excellence in Zero Energy and Resource Efficient Smart Buildings and Districts, ZEBE (grant No. 2014-2020.4.01.15-0016) funded by the European Regional Development Fund.

\section{References}

1. J. Sundell. Indoor Air. 14, 51-58 (2004)

2. D.Y.C. Leung. Front. Environ. Sci. 2, (2015)

3. U.S. Environmental Protection Agency. Building Air Quality: A guide for Building Owners and Facility Managers, 1991

4. B.A. Rock, K.A. Moylan. ASHRAE Trans. 105, 110 (1999)

5. J. Balvers, R. Bogers, R. Jongeneel, I. Van Kamp, A. Boerstra, F. Van Dijken. Archit. Sci. Rev. 55, 414 (2012)

6. J. Balvers, A. Boerstra, F. Van Dijken. 3-4 (2011)

7. J. Schnieders, A. Hermelink. Energy Policy. 34, 151-171 (2006)

8. A. Merzkirch, S. Maas, F. Scholzen, D. Waldmann. Int. J. Vent. 18, 19-27 (2017)

9. A. Merzkirch, S. Maas, F. Scholzen, D. Waldmann. Energy Build. 116, 376-383 (2016)

10. C.A. Parker, K.D. Pressnail, M.F. Touchie, D. Derose, S. Dedesko. A Study of Cross Contamination of in-Suite Ventilation Systems Used in Multi-Unit Residential Buildings, in: 14th Can. Conf. Build. Sci. Technol., 2014: pp. 369-380

11. K. Thunshelle, M. Mysen. Balanced ventilation in apartment buildings, in: Proc. 11th Int. Conf. Indoor Air Qual. Clim., 2008: pp. 3668-3673

12. S. Nagano. The Diffusion Process of Kitchen Gas Exhausted To the Outdoor Air Surrounding a MultiUnit Housing Facility, in: Proc. Build. Simul., 1999: pp. 799-806

13. A.W.K. Law, E.C.C. Choi, R.E. Britter. Atmos. Environ. 38, 3817-3825 (2004)

14. S.G. Talbert, S.M. Ricci, M.E. Goshe, L.L.S. Aume, R.L. Osborne. ASHRAE Trans. 113, 368-378 (2007)

15. G.H. Stickford, J.H. Saunders, D.J. Hesse, R.L. Osborne, S.G. Talbert. ASHRAE Trans. 108, 10171028 (2002)

16. A. Gupta, T. Stathopoulos, P. Saathoff. Atmos. Environ. 46, 496-507 (2012)

17. J. Niu, T.C.W. Tung. Indoor Air. 18, 12-26 (2008)

18. J. Mao, N. Gao. Build. Environ. 94, 516-531 (2015)

19. Z.T. Ai, C.M. Mak, D.J. Cui. Indoor Built Environ. 24, 214-224 (2015)

20. J. Wang, T. Zhang, S. Wang, F. Battaglia. Energy Build. 153, 325-340 (2017)

21. D. Mu, N. Gao, T. Zhu. Build. Environ. 137, 185197 (2018)

22. O. Seppänen, J. Railio, T. Strand. Finnish Ventilation Regulations for Better IAQ and Energy Efficiency, in: CLIMA 2016 - Proc. 12th REHVA World Congr., 2016

23. S. Zakeri Shahvari, J.D. Clark. Sci. Technol. Built Environ. 26, 552-566 (2020)

24. A. Gupta, T. Stathopoulos, P. Saathoff. ASHRAE Trans. 118, 1021-1038 (2012)

25. P. Saathoff, A. Gupta, T. Stathopoulos, L. Lazure. J. Air Waste Manag. Assoc. 59, 343-353 (2009)

26. M.F. Yassin. Energy Build. 62, 68-77 (2013)

27. P. Spiru, P.L. Simona. Energy Procedia. 128, 179186 (2017) 
28. CEN (European Committee for Standardization). EN 16798-3. Energy performance of buildings Ventilation for buildings - Part 3: For nonresidential buildings - Performance requirements for ventilation and room-conditioning systems, 2017

29. CEN (European Committee for Standardization). CEN/TR 16798-4. Energy performance of buildings - Ventilation for buildings - Part 4: Interpretation of the requirements in EN 16798- 3 - For nonresidential buildings - Performance requirements for ventilation and room-conditioning systems, 2017

30. Chartered Institution of Building Services Engineers (CIBSE). CIBSE Guide B2: Ventilation and ductwork, CIBSE Publications, 2016

31. ASHRAE. 2019 ASHRAE Handbook-HVAC Applications, 2019

32. International Code Council. International Mechanical Code, 2018

33. International Association of Plumbing and Mechanical Officials. Uniform Mechanical Code, 2018

34. Chartered Institution of Building Services Engineers (CIBSE). Minimising pollution at air intakes, 1999

35. ASHRAE. ANSI/ASHRAE Standard 62.1-2019 Ventilation for Acceptable Indoor Air Quality, ASHRAE, 2019

36. ASHRAE. ANSI/ASHRAE Standard 62.2-2019, Ventilation and Acceptable Indoor Air Quality in Residential Buildings, ASHRAE, 2019

37. J. Kurnitski, T. Carlsson, O. Seppänen, M. Thalfeldt, M. Toksoy, P.V. Bednarova, H. van Weele. Residential Heat Recovery Ventilation, 2018 